\title{
Review
}

Molecular

Neuropsychiatry
Mol Neuropsychiatry 2018;4:190-195

DOI: $10.1159 / 000495659$
Received: July 31, 2018

Accepted: November 20, 2018

Published online: January 24, 2019

\section{Social Isolation Rearing Induces \\ Neuropsychiatric Diseases: Updated Overview}

\author{
Hamidreza Famitafreshi ${ }^{\mathrm{a}}$ Morteza Karimian ${ }^{\mathrm{b}}$ \\ a Physiology Department, Tehran University of Medical Sciences - International Campus, Tehran, Iran; \\ bPhysiology Department, Tehran University of Medical Sciences, Tehran, Iran
}

\section{Keywords}

Social isolation rearing · Neuropsychiatry · Therapy and epigenetics

\begin{abstract}
Neuropsychiatric and neurologic diseases cause a great burden for individuals, families, and societies. Social isolation rearing can trigger a variety of psychiatric diseases. New advances suggest that epigenetic factors along with other neurochemical changes can be an important topic in neuropsychiatric diseases. It is thought that the prevention of social isolation rearing that occurs around birth can reduce the occurrence of neuropsychiatric diseases. It has been suggested that the environment can induce epigenetic alternation. So, for the diagnosis of a proportion of neuropsychiatric diseases, assessing epigenetic factors may be helpful. Also, apart from epigenetic factors, new advances have been made about new mechanisms of and treatments for such a disorder.

(c) 2019 S. Karger AG, Basel
\end{abstract}

\section{Introduction}

Neuropsychiatric diseases encompass a wide variety of symptoms that are the cause of great morbidity and disability. Overall, the prevalence of psychiatric disorders is estimated to be $6.7 \%$ [1]. Psychiatric disorders, especially in childhood and adolescence, encompass anxiety (3.2\%), depression (6.2\%), eating disorders (4.4\%), autism spectrum disorders (16.1\%), attention-deficit/hyperactivity disorder (5.5\%), and conduct disorder (5\%) [1]. Many studies have been performed to elucidate the basic molecular mechanism that is responsible for the occurrence of such diseases.

Recent studies have shown that early-life experiences can influence adulthood behavior [2]. This is important because in this way we can show that genetics is not the only factor that influences the behavior of the organism in adulthood [3]. Also, it implies that nurturance is an important factor that influences adulthood behavior [4]. Although many studies support the theory that genetics is an important factor that influences behavior in adulthood, environmental factors can also be important as independent factors that influence behavior in adulthood [5]. Important findings of recent studies about the etiology of neuropsychiatric diseases suggest that the neurobiological mechanisms underlying these abnormalities have been discovered.

\section{KARGER}

(C) 2019 S. Karger AG, Basel

E-Mail karger@karger.com

www.karger.com/mnp
Morteza Karimian

Physiology Department

Tehran University of Medical Sciences

Tehran (Iran)

E-Mail karimian@tums.ac.ir 


\section{Behavioral Changes}

In later stages of life, a wide variety of behavioral abnormities develop after social isolation rearing. Here, we mention neuropsychiatric abnormalities that can develop after social isolation rearing.

\section{Anxiety}

Recent studies suggest that anxiety will be increased by social isolation rearing. The increase in anxiety is caused by the alternation of neuroplasticity [6].

\section{Depression}

Depression is another disorder that occurs in social isolation reared male Sprague-Dawley rats. This behavior was assessed after 107 days of social isolation. This disorder originates in the serotonergic system and adrenergic system [7].

\section{Impulsivity}

Impulsivity, a symptom that occurs in some childhood psychiatric disorders, develops in social isolation reared male Lister Hooded rats. The duration of social isolation was 23 days [8].

\section{Schizophrenia}

This type of neuropsychiatric disorder also increases in social isolation rearing. Since schizophrenia manifests as a constellation of symptoms such as polydipsia, reversal learning, impaired prepulse inhibition, and many others, animal studies have focused on these symptoms. Investigating the occurrence of this disorder, polydipsia in male Sprague-Dawley rats after 62 days of social isolation [9], reversal learning in male Sprague-Dawley rats after 52 days of social isolation [10], and prepulse inhibition in male Wistar rats after 21 days of social isolation [11] were assessed. It was seen that schizophrenia-related symptoms occurred in social isolation reared rats. Also, oxidative stress disturbance, as a result of 8 weeks of social isolation rearing, increases the incidence of schizophrenia in male Sprague-Dawley rats [12].

\section{Pain}

Pain is also another behavior that is influenced by social isolation rearing. In one study, it has been shown that allodynia was reduced in a mice model of chronic inflammatory pain [13].

\section{Cognitive Function}

Another brain function that is influenced by social isolation rearing is memory. Different kinds of memory, assessed by the Morris water maze in male mice after 4 weeks of social isolation [14] and by the novel object recognition test in female Lister Hooded rats after 28 days of social isolation, were impaired [15]. Also, attention that is needed for proper cognitive performance was disturbed in socially isolated male Sprague-Dawley rats [16].

\section{Addictive Behaviors}

Addiction is a complex disorder with many adverse effects for the addicts and also for the society [17]. For the development of addiction, circuits that control pleasure are disturbed [18]. Normally, reward and anti-reward are in balance with each other [19]. The important point is the evaluation tool that assesses the brain circuits that involve these behaviors. Sucrose consumption is one of them that, in social isolation reared rats, has been shown to be altered [20]. The adrenergic and dopaminergic system has been shown to be increased in the nucleus accumbens area in male Long-Evans rats that were socially isolated for 6 weeks [21].

\section{Other Behaviors}

Other behavior can also be negatively affected by social isolation rearing. In fish, social isolation rearing induces continued fights [22]. In another experiment in rodents, social isolation rearing disturbed male-male social interaction [23].

\section{The Mechanisms behind Social Isolation Rearing- Induced Neuropsychiatric Disorders}

\section{Epigenetic Changes versus Polymorphism}

Assessing the Role of the Environment

Previously, the biopsychosocial model, both in philosophy and clinical practice, illustrated well how suffering, disease, and illness are affected by multiple levels of organization, from societal to molecular organization [24]. This model confirmed that the environment can change the behavior of an organism especially in early life [25]. However, at that time, because of a lack of knowledge, some important concepts were missing. For delineating the impact of environment, we discuss two important concepts in genetics: polymorphism and epigenetic changes. Susceptibility for the emergence of neuropsychiatric disorders is determined by the complex interaction of environment and genetic susceptibility. 
The same condition does not trigger the development of neuropsychiatric diseases in all individuals, many studies have been conducted to find out the reason. It is believed that the environmental conditions prone an individual to show neuropsychiatric symptoms in a genetically susceptible organism. The susceptibility can happen through polymorphism and epigenetic modifications. Polymorphism makes some individuals susceptible to develop neuropsychiatric diseases with less influence of the environment (genetically determined polymorphism) [26], but it is believed that the environment triggers an individual to develop neuropsychiatric diseases through epigenetic modifications [27]. Genetic diversity or polymorphism is defined as the occurrence of neuropsychiatric disorders in the context of genetic diversity among individuals. Genetic diversity expresses itself as the occurrence of neuropsychiatric diseases not in all high-risk people. Epigenetic diversity has been well established in previous studies $[28,29]$. Set apart from this are epigenetic factors that are defined as the cause of psychiatric disorders after the occurrence of some genetic modifications in the genetic material. A recent study attributed this to environmental modalities [30].

The behavioral changes that occur as the consequences of social isolation rearing can emphasize the role of environment on behavior. However, an important issue in this regard is epigenetics. Epigenetics, however, has recently been attributed great importance for abnormalities that occur around birth $[31,32]$. Alternations of DNA function, as a consequence of epigenetics, do not affect the DNA sequence but instead they encompass chemical changes in the DNA composition that result in changes in transcription and modification of proteins [33]. Epigenetic changes do not involve DNA mutation. This is important because epigenetic changes occur with every change in the environment, and maybe they are reversible, but they may also cause permanent changes in bodily functions [34].

Epigenetics involves DNA methylation, histone modification, and non-coding RNAs [35]. There is some evidence that shows that epigenetic modifications can influence the development of the brain [36]. Many studies support the concept of microRNAs as a biomarker of psychiatric diseases [37, 38]. However, in order to determine if social isolation rearing can produce a biomarker that can predict the occurrence of psychiatric diseases in adulthood, more studies should be done. However, because of a lack of proper in vitro models, the detailed mechanism for such modifications is not well understood [36]. Recent studies support the evidence that with the application of stem cell treatment new advances in the understanding of epigenetics about brain development can be achieved [39]. The problems in this regard are the modeling of the proper microenvironment that can be the same as the microenvironment of the developing brain. The most challenging issue in these studies is glial cells [40].

\section{Neurobiological Mechanism and Brain Areas}

Behavioral and neurobiological changes that occur as the result of social isolation rearing occur in different brain regions. In several studies, the prefrontal cortex received great attention. Prefrontal cortex malfunctions have been demonstrated to be induced by a variety of mechanisms. Affected are NMDA receptors in mice after 3 months of social isolation [41], interneurons in mice [42], and central cannabinoid, serotonergic, and cholinergic systems in rats [43]. Aggressive behavior is influenced by social isolation rearing through prefrontal cortex activation [44]. The hippocampus is another brain region that is influenced by social isolation rearing. The hippocampus has been shown to be important for tolerating social isolation stress in rats that were isolated for 6 weeks [45]. Also, the serotonergic system in the hippocampus is affected by social isolation stress, since the maturation of these systems occurs 30 to 50 days postnatally [46]. After 6 weeks of social isolation rearing, the GABAergic neurons in the hippocampus have been shown to be affected in mice [47]. Eight weeks of social isolation rearing influences fear-learning, a behavior that is regulated by the hippocampus in male wild-type C57BL/6J mice [48]. Responses of the prefrontal cortex to another brain region are affected by social isolation rearing [49].

The amygdala is another brain region that is important for assessing the outcome of social isolation rearing. Inhibitory neurons of the amygdala in a rat model of schizophrenia [50], pyramidal neurons of the amygdala in male Long-Evans rats after 24 days of social isolation [51], and brain-derived neurotrophic factor (BDNF) signaling in the amygdala in rats after 4 weeks of social isolation [52] were all affected by social isolation rearing. Limbic system remodeling with selective prefrontal cortex volume loss has been shown to be involved in producing schizophrenic-like symptoms in socially isolated rats [53]. Eight weeks of social isolation rearing affects the striatum as part of the basal ganglia which is important for the movement control in rats [54]. Experiments have shown that the dopaminergic system in the striatum responds to 50 days of social isolation rearing in rats [55]. 
The dorsal raphe is another brain region that is affected by one month of social isolation rearing in male mice [56]. The dopaminergic neurons in the dorsal raphe have been shown to be involved after social isolation rearing in mice [57]. It should be noted that different types of rats (Wistar and Lister Hooded rats) respond differently to 6-8 weeks of social isolation rearing with regard to neurotransmitter release in different brain regions [58]. So, it can be concluded that a complex pathophysiology underlies the occurrence of such diseases.

\section{Therapeutic Strategies}

Since social isolation rearing causes a constellation of neurologic and psychiatric disorders, it is necessary to look for effective treatments for curing the core symptoms. Based on recent advances, treatments can be divided into two groups: medication therapy and environmental modalities. Treatment with medication is directed at antioxidant therapy, antipsychotic therapy, and antidepressants. Environmental modalities can combat against social isolation rearing [59]. Enriching the environment has a positive effect on the negative impact of social isolation rearing $[60,61]$. Drug therapy is directed at the ap- plication of antidepressants like fluoxetine $[62,63]$, antipsychotics like clozapine $[64,65]$, and antioxidant therapeutics like $\mathrm{N}$-acetyl cysteine [66]. The antagonist of cannabinoids has been shown to be effective for the longlasting treatment of psychotic symptoms [67]. Disturbance of the immune system after social isolation rearing points toward therapy that is directed at immune system abnormalities [68, 69].

\section{Conclusion}

This overview suggests that social isolation rearing causes different symptoms of psychiatric diseases. New studies support the involvement of epigenetic factors in such disorders, but this important issue has not yet been the topic of recent studies. However, many advances have been achieved in knowing the pathophysiology and treatment of social isolation rearing disorders.

\section{Disclosure Statement}

The authors have no conflicts of interest to declare.

\section{References}

1 Erskine HE, Baxter AJ, Patton G, Moffitt TE, Patel V, Whiteford HA, et al. The global coverage of prevalence data for mental disorders in children and adolescents. Epidemiol Psychiatr Sci. 2017 Aug;26(4):395-402.

2 Fone KC, Porkess MV. Behavioural and neurochemical effects of post-weaning social isolation in rodents-relevance to developmental neuropsychiatric disorders. Neurosci Biobehav Rev. 2008 Aug;32(6):1087-102.

3 Larsson H, Tuvblad C, Rijsdijk FV, Andershed H, Grann M, Lichtenstein P. A common genetic factor explains the association between psychopathic personality and antisocial behavior. Psychol Med. 2007 Jan;37(1): 15-26.

4 Dishion TJ, Bullock BM. Parenting and adolescent problem behavior: an ecological analysis of the nurturance hypothesis. 2002.

5 Stern PC. New environmental theories: toward a coherent theory of environmentally significant behavior. J Soc Issues. 2000;56(3): $407-24$.

6 Lukkes JL, Watt MJ, Lowry CA, Forster GL. Consequences of post-weaning social isolation on anxiety behavior and related neural circuits in rodents. Front Behav Neurosci. 2009 Aug;3:18.
7 Brenes JC, Rodríguez O, Fornaguera J. Differential effect of environment enrichment and social isolation on depressive-like behavior, spontaneous activity and serotonin and norepinephrine concentration in prefrontal cortex and ventral striatum. Pharmacol Biochem Behav. 2008 Mar;89(1):8593.

8 Liu YP, Wilkinson LS, Robbins TW. 'Waiting impulsivity' in isolation-reared and sociallyreared rats: effects of amphetamine. Psychopharmacology (Berl). 2017 May;234(9-10): 1587-601.

9 Hawken ER, Delva NJ, Beninger RJ. Increased drinking following social isolation rearing: implications for polydipsia associated with schizophrenia. PLoS One. 2013;8(2):e56105.

10 Powell SB, Khan A, Young JW, Scott CN, Buell MR, Caldwell S, et al. Early adolescent emergence of reversal learning impairments in isolation-reared rats. Dev Neurosci. 2015; 37(3):253-62.

11 Rosa ML, Silva RC, Moura-de-Carvalho FT, Brandão ML, Guimarães FS, Del Bel EA. Routine post-weaning handling of rats prevents isolation rearing-induced deficit in prepulse inhibition. Braz J Med Biol Res. 2005 Nov; 38(11):1691-6.
12 Möller M. Oxidative status in rats exposed to social isolation rearing: behavioral pharmacology studies and relevance for schizophrenia: North-West University; 2009.

13 Horiguchi N, Ago Y, Hasebe S, Higashino K, Asada K, Kita Y, et al. Isolation rearing reduces mechanical allodynia in a mouse model of chronic inflammatory pain. Pharmacol Biochem Behav. 2013 Nov;113:46-52.

14 Ibi D, Takuma K, Koike H, Mizoguchi H, Tsuritani K, Kuwahara Y, et al. Social isolation rearing-induced impairment of the hippocampal neurogenesis is associated with deficits in spatial memory and emotion-related behaviors in juvenile mice. J Neurochem. 2008 May; 105(3):921-32.

15 McLean S, Grayson B, Harris M, Protheroe C, Woolley $\mathrm{M}$, Neill J. Isolation rearing impairs novel object recognition and attentional set shifting performance in female rats. J Psychopharmacol. 2010 Jan;24(1):57-63.

16 Marriott AL. Effects of neonatal domoic acid treatment and social isolation rearing on measures of attentional processing in rats. University of Prince Edward Island; 2014. 
17 Woodworth AM, McLellan AT. Converging advances in science, policy and public awareness: A time of great opportunity and change in addiction treatment. Brain Res Bull. 2016 May;123:110-3.

18 Kennett J, Matthews S, Snoek A. Pleasure and addiction. Front Psychiatry. 2013 Sep;4:117.

19 Koob GF. Dynamics of neuronal circuits in addiction: reward, antireward, and emotional memory. Pharmacopsychiatry. 2009 May; 42(S 01 Suppl 1):S32-41.

20 Hall FS, Humby T, Wilkinson LS, Robbins TW. The effects of isolation-rearing on sucrose consumption in rats. Physiol Behav. 1997 Aug;62(2):291-7.

21 Karkhanis AN, Locke JL, McCool BA, Weiner $\mathrm{JL}$, Jones SR. Social isolation rearing increases nucleus accumbens dopamine and norepinephrine responses to acute ethanol in adulthood. Alcohol Clin Exp Res. 2014 Nov;38(11): 2770-9.

22 Ichihashi T, Ichikawa Y, Matsushima T. A non-social and isolate rearing condition induces an irreversible shift toward continued fights in the male fighting fish (Betta splendens). Zool Sci. 2004 Jul;21(7):723-9.

23 Keesom SM, Finton CJ, Sell GL, Hurley LM. Early-life social isolation influences mouse ultrasonic vocalizations during male-male social encounters. PLoS One. 2017 Jan; 12(1):e0169705.

24 Borrell-Carrió F, Suchman AL, Epstein RM. The biopsychosocial model 25 years later: principles, practice, and scientific inquiry. Ann Fam Med. 2004 Nov-Dec;2(6):576-82.

25 Daskalakis NP, Bagot RC, Parker KJ, Vinkers $\mathrm{CH}$, de Kloet ER. The three-hit concept of vulnerability and resilience: toward understanding adaptation to early-life adversity outcome. Psychoneuroendocrinology. 2013 Sep;38(9): 1858-73.

26 Clark W. The environment and the genotype in polymorphism. Zool J Linn Soc. 1976; 58(3):255-62.

27 Jirtle RL, Skinner MK. Environmental epigenomics and disease susceptibility. Nat Rev Genet. 2007 Apr;8(4):253-62.

28 McAllister TW, Summerall L. Genetic polymorphisms in the expression and treatment of neuropsychiatric disorders. Curr Psychiatry Rep. 2003 Oct;5(5):400-9.

29 Kim DK, Lim SW, Lee S, Sohn SE, Kim S, Hahn CG, et al. Serotonin transporter gene polymorphism and antidepressant response. Neuroreport. 2000 Jan;11(1):215-9.

30 Caspi A, Hariri AR, Holmes A, Uher R, Moffitt TE. Genetic sensitivity to the environment: the case of the serotonin transporter gene and its implications for studying complex diseases and traits. Am J Psychiatry. 2010 May;167(5):509-27.

31 Guérout N, Li X, Barnabé-Heider F. Cell fate control in the developing central nervous system. Exp Cell Res. 2014 Feb;321(1):77-83.
32 Tsankova N, Renthal W, Kumar A, Nestler EJ. Epigenetic regulation in psychiatric disorders. Nat Rev Neurosci. 2007 May;8(5):35567.

33 Dupont C, Armant DR, Brenner CA, editors. Epigenetics: definition, mechanisms and clinical perspective. Seminars in reproductive medicine. NIH Public Access; 2009.

34 Gapp K, von Ziegler L, Tweedie-Cullen RY, Mansuy IM. Early life epigenetic programming and transmission of stress-induced traits in mammals: how and when can environmental factors influence traits and their transgenerational inheritance? BioEssays. 2014 May;36(5):491-502.

35 Bird A. Perceptions of epigenetics. Nature. 2007 May;447(7143):396-8.

36 Keverne EB, Pfaff DW, Tabansky I. Epigenetic changes in the developing brain: effects on behavior. Proc Natl Acad Sci USA. 2015 Jun; 112(22):6789-95.

37 Narahari A, Hussain M, Sreeram V. MicroRNAs as biomarkers for psychiatric conditions: a review of current research. Innov Clin Neurosci. 2017 Feb;14(1-2):53-5.

38 Weiland M, Gao XH, Zhou L, Mi QS. Small RNAs have a large impact: circulating microRNAs as biomarkers for human diseases. RNA Biol. 2012 Jun;9(6):850-9.

39 Bellin M, Marchetto MC, Gage FH, Mummery CL. Induced pluripotent stem cells: the new patient? Nat Rev Mol Cell Biol. 2012 Nov; 13(11):713-26.

40 Di Giorgio FP, Boulting GL, Bobrowicz S, Eggan KC. Human embryonic stem cell-derived motor neurons are sensitive to the toxic effect of glial cells carrying an ALS-causing mutation. Cell Stem Cell. 2008 Dec;3(6):63748.

41 Castillo-Gómez E, Pérez-Rando M, Bellés M, Gilabert-Juan J, Llorens JV, Carceller H, et al. Early social isolation stress and perinatal NMDA receptor antagonist treatment induce changes in the structure and neurochemistry of inhibitory neurons of the adult amygdala and prefrontal cortex. Eneuro. 2017; 4(2):ENEURO. 0034-17.2017. https://doi. org/10.1523/ENEURO.0034-17.2017.

42 Ueno H, Suemitsu S, Murakami S, Kitamura $\mathrm{N}$, Wani K, Okamoto M, et al. Region-specific impairments in parvalbumin interneurons in social isolation-reared mice. Neuroscience. 2017 Sep;359:196-208.

43 Khan A. Behavioural and neurochemical changes in the isolation-reared rats following administration of phamacological ligands acting at central cannabinoid, serotonergic and cholinergic systems. University of Nottingham; 2014.

44 Goodell DJ, Ahern MA, Baynard J, Wall VL, Bland ST. A novel escapable social interaction test reveals that social behavior and $\mathrm{mPFC}$ activation during an escapable social encounter are altered by post-weaning social isolation and are dependent on the aggressiveness of the stimulus rat. Behav Brain Res. 2017 Jan; 317:1-15.
45 Muchimapura S, Fulford AJ, Mason R, Marsden CA. Isolation rearing in the rat disrupts the hippocampal response to stress. Neuroscience. 2002;112(3):697-705.

46 Muchimapura S, Marsden C. The effect of social isolation rearing on the development of the hippocampus and serotonergic function. Thai J Physiol Sci. 2004;17:1-8.

47 Talani G, Biggio F, Licheri V, Locci V, Biggio $\mathrm{G}$, Sanna E. Isolation rearing reduces neuronal excitability in dentate gyrus granule cells of adolescent C57BL/6J mice: role of GABAergic tonic currents and neurosteroids. Front Cell Neurosci. 2016 Jun;10:158

48 Gresack JE, Risbrough VB, Scott CN, Coste S, Stenzel-Poore M, Geyer MA, et al. Isolation rearing-induced deficits in contextual fear learning do not require $\mathrm{CRF}(2)$ receptors. Behav Brain Res. 2010 May;209(1):80-4.

49 Peters YM, O'Donnell P. Social isolation rearing affects prefrontal cortical response to ventral tegmental area stimulation. Biol Psychiatry. 2005 May;57(10):1205-8.

50 Gilabert-Juan J, Moltó MD, Nacher J. Postweaning social isolation rearing influences the expression of molecules related to inhibitory neurotransmission and structural plasticity in the amygdala of adult rats. Brain Res. 2012 Apr;1448:129-36.

51 Rau AR, Chappell AM, Butler TR, Ariwodola OJ, Weiner JL. Increased basolateral amygdala pyramidal cell excitability may contribute to the anxiogenic phenotype induced by chronic early-life stress. J Neurosci. $2015 \mathrm{Jul}$; 35(26): $9730-40$.

52 Wall VL. Isolation rearing alters behavior and expression of brain-derived neurotrophic factor and the immediate early gene arc in the prefrontal cortex and amygdala of male and female rats. University of Colorado at Denver; 2012.

53 Schubert MI, Porkess MV, Dashdorj N, Fone $\mathrm{KC}$, Auer DP. Effects of social isolation rearing on the limbic brain: a combined behavioral and magnetic resonance imaging volumetry study in rats. Neuroscience. $2009 \mathrm{Mar}$ 159(1):21-30.

54 Möller M, Du Preez JL, Emsley R, Harvey BH. Isolation rearing-induced deficits in sensorimotor gating and social interaction in rats are related to cortico-striatal oxidative stress, and reversed by sub-chronic clozapine administration. Eur Neuropsychopharmacol. 2011 Jun;21(6):471-83.

55 Yorgason JT, Calipari ES, Ferris MJ, Karkhanis AN, Fordahl SC, Weiner JL, et al. Social isolation rearing increases dopamine uptake and psychostimulant potency in the striatum. Neuropharmacology. 2016 Feb;101:471-9.

56 Maekawa T, Kim S, Nakai D, Makino C, Takagi $\mathrm{T}$, Ogura $\mathrm{H}$, et al. Social isolation stress induces ATF-7 phosphorylation and impairs silencing of the 5-HT 5B receptor gene. EMBO J. 2010 Jan;29(1):196-208. 
57 Matthews GA, Nieh EH, Vander Weele CM, Halbert SA, Pradhan RV, Yosafat AS, et al. Dorsal raphe dopamine neurons represent the experience of social isolation. Cell. 2016 Feb;164(4):617-31.

58 Trabace L, Zotti M, Colaianna M, Morgese MG, Schiavone S, Tucci P, et al. Neurochemical differences in two rat strains exposed to social isolation rearing. Acta Neuropsychiatr. 2012 Oct;24(5):286-95.

59 Li N, Ping J, Wu R, Wang C, Wu X, Li L. Auditory fear conditioning modulates prepulse inhibition in socially reared rats and isolation-reared rats. Behav Neurosci. 2008 Feb; 122(1):107-18.

60 Varty GB, Paulus MP, Braff DL, Geyer MA. Environmental enrichment and isolation rearing in the rat: effects on locomotor behavior and startle response plasticity. Biol Psychiatry. 2000 May;47(10):864-73.

61 Tanaś $Ł$, Ostaszewski P, Iwan A. Effects of post-weaning social isolation and environment al enrichment on exploratory behavior and ankiety in Wistar rats. Acta Neurobiol Exp (Wars). 2015;75(1):72-9.
62 Brenes JC, Fornaguera J. The effect of chronic fluoxetine on social isolation-induced changes on sucrose consumption, immobility behavior, and on serotonin and dopamine function in hippocampus and ventral striatum. Behav Brain Res. 2009 Mar;198(1):199-205.

63 Liu F, Liu YP, Lei G, Liu P, Chu Z, Gao CG, et al. Antidepressant effect of recombinant NT4-NAP/AAV on social isolated mice through intranasal route. Oncotarget. 2017 Feb;8(6):10103-13.

64 Yang SN, Yang YY, Wan FJ, Huang CL, Liu YP. Effects of isolation rearing and early antipsychotic intervention on oxidative stress-induced apoptosis and brain-derived neurotrophic factor in hippocampus in a rat model of schizophrenia. Journal of Medical Sciences. 2017;37(4):155.

65 Möller M, Du Preez JL, Emsley R, Harvey BH. Social isolation rearing in rats alters plasma tryptophan metabolism and is reversed by sub-chronic clozapine treatment. Neuropharmacology. 2012 Jun;62(8):2499-506.
66 Möller M, Du Preez JL, Viljoen FP, Berk M, Harvey BH. N-Acetyl cysteine reverses social isolation rearing induced changes in corticostriatal monoamines in rats. Metab Brain Dis. 2013 Dec;28(4):687-96.

67 Zamberletti E, Viganò D, Guidali C, Rubino $\mathrm{T}$, Parolaro D. Long-lasting recovery of psychotic-like symptoms in isolation-reared rats after chronic but not acute treatment with the cannabinoid antagonist AM251. Int J Neuropsychopharmacol. 2012 Mar;15(2):267-80.

68 Möller M, Du Preez JL, Viljoen FP, Berk M, Emsley R, Harvey BH. Social isolation rearing induces mitochondrial, immunological, neurochemical and behavioural deficits in rats, and is reversed by clozapine or N-acetyl cysteine. Brain Behav Immun. 2013 May;30:15667.

69 Ko CY, Liu YP. Isolation rearing impaired sensorimotor gating but increased pro-inflammatory cytokines and disrupted metabolic parameters in both sexes of rats. Psychoneuroendocrinology. 2015 May;55:173-83. 